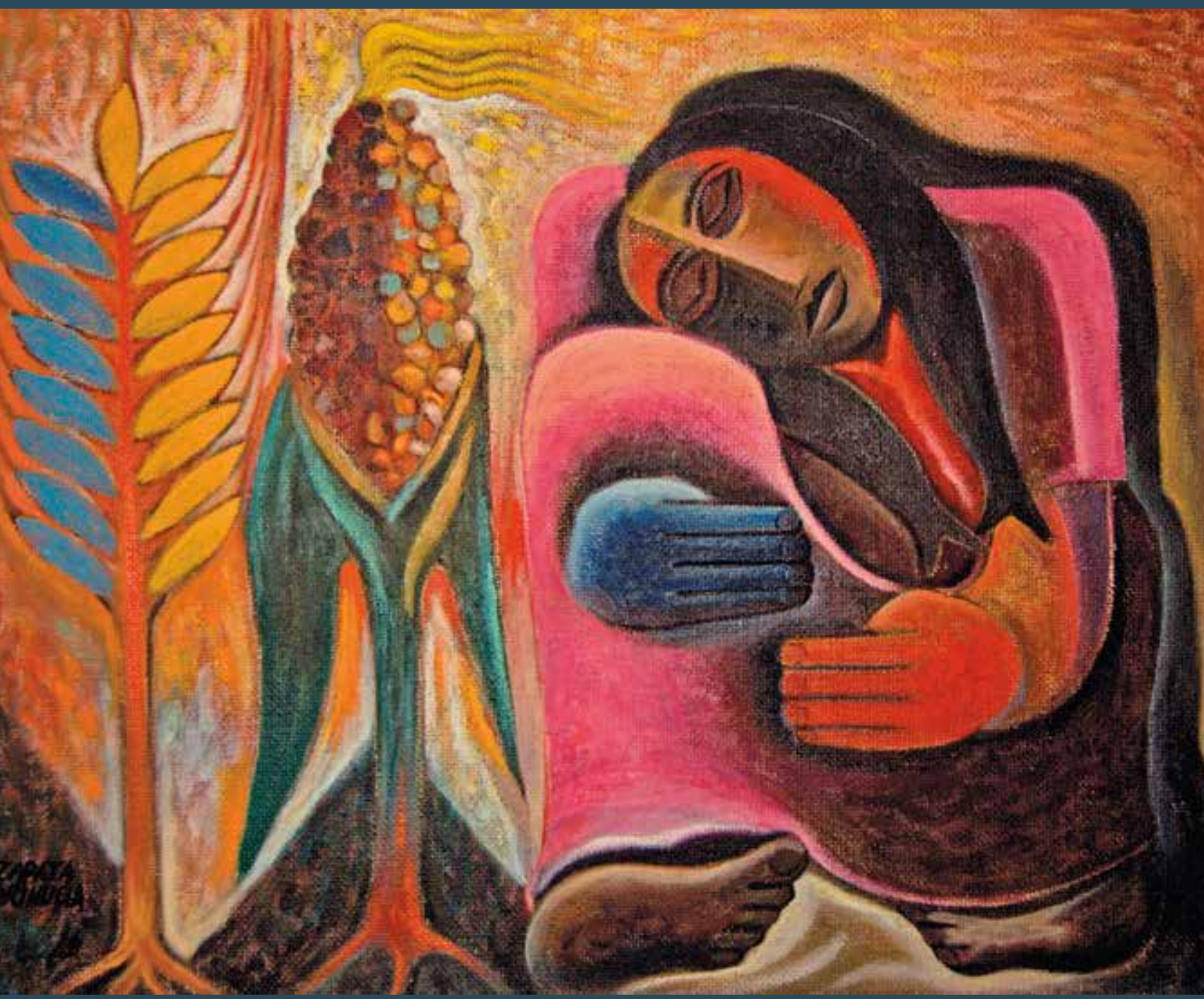

Manuel Zapata Orihuela. El Sueño de una Campesina, 1985. Óleo / lienzo, 100 X 81 cm. 


\section{Manuel Zapata-Orihuela. Espacios donde conviven el tiempo y la memoria}

María del Socorro MoraC de Asmat

Universidad Complutense de Madrid

En la entrevista realizada en abril del 2015 al maestro de la pintura peruana Manuel ZapataOrihuela, conversamos no sólo de su vida y su obra o su posición neuroestética, sino de su preocupación por la situación mundial y su visión espiritual y trascendental.

Palabras clave: Zapata-Orihuela, arte, Indigenismo, neuroestética, entrevista, memoria, espacio, tiempo.

In the interview realized in April 2015 with the master of Peruvian painting Manuel ZapataOrihuela, we talked not only of his life and work or neuroaesthetic position, but also of his concern about the global situation, and his spiritual and transcendental vision.

Keywords: Zapata-Orihuela, art, Indigenismo, neuroaesthetics, interview, memory, space, time.

Lo que dejamos atrás y lo que tenemos por delante no son nada comparado con lo que llevamos dentro.

Ralph Waldo Emerson

El Indigenismo fue una corriente no sólo pictórica sino cultural e intelectual, como escribía su fundador José Sabogal: "Sí, somos indigenistas en el justo significado de la palabra y más aún, indigenistas culturales, pues buscamos nuestra identidad integral con nuestro suelo, su humanidad y nuestro tiempo" ${ }^{1}$. Iniciamos estas reflexiones acerca de la vida y obra del pintor peruano Manuel Zapata-Orihuela, recordando que este maestro de la plástica peruana tiene un nexo con esta corriente artística, pero que su amor y dedicación hacia el quehacer artístico van más allá de las corrientes, las modas o los continentes. Sin duda, la mayor felicidad de un ser humano es ser y hacer lo que verdaderamente le apasiona y a ese grupo selecto de personas autotélicas ${ }^{2}$ pertenece nuestro artista que, con el equipaje que

1 Román, 2004: 19.

2 Para Csikszentmihalyi (2007: 145), una persona autotélica es aquella que realiza algo no por una recompensa externa sino por una motivación interior. Su postura, como la de otros psicólogos positivistas, está inspirada en Abraham Maslow. 
ha transportado dentro de sí, desde su lejana tierra, ha seguido produciendo sin importarle lo efímero del éxito, el fracaso o las direcciones de grupos, porque como dice Lucie-Smith:

Aquellos que ahora son mejor recordados, y que de un modo u otro parecen haber contribuido de manera significativa a nuestra comprensión de la sensibilidad latinoamericana contemporánea, eran en esencia individualistas ${ }^{3}$.

No podemos ser, sin embargo, tan románticos como Winston Churchill ${ }^{4}$ porque muchas veces lo que pintamos puede que tenga diversos significados, como dice Sérvulo Gutiérrez:

Lo que esperamos de la pintura es lo que parezca bien traernos: sea una especulación metafísica, un amargo comentario de la verdad, un simple hallazgo plástico, una sensación de belleza ${ }^{5}$.

Y desde el punto de vista de la emoción, la recompensa y la postura neuroestética que quiera adoptar cada artista, las palabras de Adreinne Rich son de una vital importancia hoy en día:

El arte es ambas cosas: duro y frágil. Hablo de lo que deseamos oír y de lo que tememos encontrar. Su fuente y genuino impulso, la imaginación, puede ser encadenada nada más nacer, pero puede liberarse en condiciones que ofrecen poco al espíritu ${ }^{6}$.

Escribir sobre Zapata-Orihuela a raíz de la entrevista que efectuamos en su taller de Gentilly (Francia), significa no solo enfocarnos en su vida y en su obra, sino que es un motivo para reflexionar acerca de más de medio siglo de avatares, circunstancias y personas que influyeron en las decisiones que hicieron que el maestro se alejara de su tierra, sin que por ello el "invisible cordón umbilical7" que le unía a ella se cortase, pese a la distancia y el tiempo. Desde el punto de vista neuroestético, todos llevamos dentro un

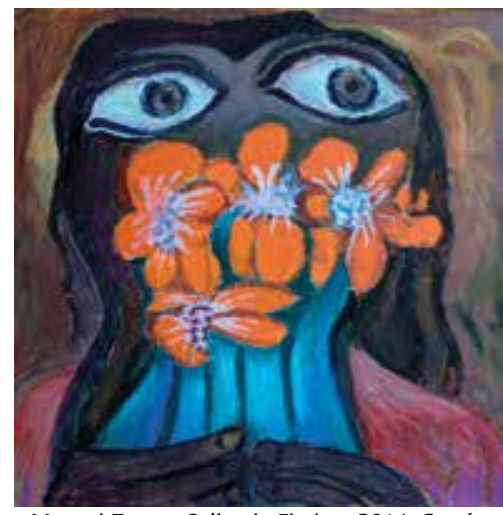

Manuel Zapata Orihuela.Florista, 2014. Cartón Encáustica, $30 \times 30 \mathrm{~cm}$. espacio en el que conviven el tiempo y la memoria de nuestro ayer: esa pequeña estructura implicada en el aprendizaje, los recuerdos y la neurogénesis ${ }^{8}$, situada dentro del lóbulo temporal intermedio, perteneciente al sistema límbico (que es el encargado de regular nuestras emociones), y que es conocida como hipocampo, por su semejanza con el caballito de mar. Zapata-Orihuela es un ser privilegiado que ha sabido transformar creativamente sus nostalgias en belleza; teniendo además muy claro que: "El arte debe tener un propósito, un lema. El artista no puede ser indiferente a la vida, a los demás". Sin duda, este maestro de la plástica peruana ha tenido activo no sólo su hipocampo, sino sus neuronas espejo y sus neuronas von Economo, encargadas de regular la

3 Lucie-Smith, 1994: 21.

4 Churchill en una conocida frase dice: "Felices los pintores, porque nunca estarán solos. Luz y color, paz y esperanza, les harán compañía hasta el fin”, pero no todos los artistas tienen esa percepción de este gran aficionado al arte y las posiciones acerca de las conexiones entre la creatividad, la felicidad y la melancolía aún son contrapuestas como hemos constatado en nuestro trabajo "Creatividad \& Melancolía. Un estudio psicobiológico de las dimensiones de la personalidad en el artista plástico contemporáneo” (MoraC, 2015).

5 Mujica, 2006: 227.

6 Rich, 2005: 50.

7 Las palabras Zapata-Orihuela entre comillas, así como las citas del maestro que mencionamos en este texto han sido extraídas de la entrevista que tuvimos con él, un Viernes Santo (3 de abril, 2015) en su casa de Gentilly, Francia.

8 Casafont, 2012:100. 
empatía y la consciencia social ${ }^{9}$, aunque ahora sabemos que no todas las experiencias son recordadas de la misma forma; son más permanentes aquellas que tienen un alto contenido emocional, otras podemos recordarlas sólo durante un tiempo ya que desaparecen posteriormente ${ }^{10}$.

En la década que nació Zapata-Orihuela (Lima, 1921), se estaba gestando en Perú un movimiento artístico que, pese a ser heredero de la cultura europea, dirigió su mirada hacia lo que estaba aconteciendo en nuestra propia realidad:

El Indigenismo significó un vuelco total del espíritu pictórico nacional y una afirmación de lo nuestro frente a lo foráneo. El que exageraciones de concepto o ceguera de dogmas, en el calor del combate, lo llevaran hasta extremos del chauvinismo y el autoaislamiento, no es imputable a la doctrina en sí, ni tal vez siquiera a sus sostenedores. Fue más bien producto de la táctica y las estrategias de una guerra que el Grupo sostuvo contra la memez del medio limeño, y que, como toda guerra, tuvo que conllevar dureza e intransigencia banderiza ${ }^{11}$.

Para Natalia Majluf: "El indigenismo no es ni una simple exaltación de lo local ni un simple exotismo.

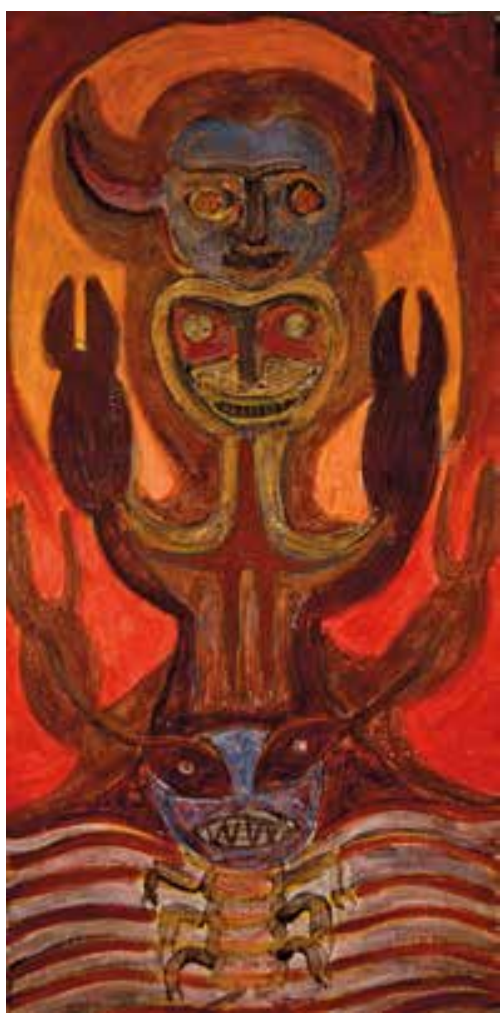

Manuel Zapata Orihuela. Máscaras, 1980. Óleo / lienzo, 56 x $27 \mathrm{~cm}$. Es más bien un autoctonismo cargado de angustias ${ }^{12}$ ". Sus palabras nos remiten al sistema neurobiológico del miedo ${ }^{13}$, que no siempre es posible contrastar con la realidad, porque nosotros encontraremos diversos mensajes - algunos con una gran carga de alegría y energía como la que nos transmite la obra de Zapata-Orihuela- en los artistas que pertenecen o se identificaron con esta corriente de la plástica peruana que según los críticos como Lauer duró poco porque: "Sabogal y su movimiento envejecieron antes de tiempo, en el sentido que vieron sus relaciones con el cambio social deseado neutralizadas, cuando fueron recuperados e ingresaron en el área de lo seguro en el mercado plástico ${ }^{14}$ ". Con respecto a estos hechos Ugarte Eléspuru escribe:

...hacia el año 1938, el panorama era diferente; ya se hacía sentir en el ambiente artístico nacional un definido movimiento de resistencia contra el Indigenismo, que como escuela pictórica, había devenido en expresión artística oficial ${ }^{15}$.

Y en medio de esa circunstancia, del inminente colapso del Indigenismo, justamente en el año 1943, es cuando Zapata-Orihuela ingresa en la Escuela Nacional de Bellas Artes de Lima

9 Moya-Albiol, Herrero \& Bernal, 2010: 89-100.

10 Punset, 2011: Entrevista a Joaquim Fuster.

11 Ugarte Eléspuru, 1970: 32.

12 Buntix \& Wuffarden, 2003: 17.

13 El eje principal de este sistema es la amígdala cerebral. Toda la información que entra a través de los sentidos pasa por la amígdala, y ésta detecta cualquier señal de peligro.

14 Lauer, 1992: 75.

15 Ugarte Eléspuru, 1970: 34. 
y comienza su andadura oficial en el arte, porque como nos relata el maestro al rememorar su infancia y juventud, lo suyo fue una necesidad interior muy temprana, que se convirtió en su profesión y a la cual ha dedicado toda su pasión:

Me gustaba hurgar en los huecos buscando arañas y observar sus telas o jugar con las abejas por simple curiosidad. He vivido en la sierra desde los 2 a los 7 años y me encantaba jugar con el agua o pescar en el río Mantaro de Huancayo, observando la naturaleza y sintiendo el viento. Pude llegar a ser ingeniero hidráulico, porque me fascina todo el movimiento de los ríos y la distribución del agua. Dibujaba con tizas en las veredas y los vecinos me decían que las ensuciaba. Sin embargo, un vecino italiano se dio cuenta de mi talento y les dijo a mis abuelos que era un orgullo que su nieto sea dibujante. A mi abuela paterna le gustaba que dibuje, también tenía un primo que pintaba por afición. A los 10 años, más o menos, ya hacía copias porque mi abuela me regaló una caja de pinturas. Comencé como autodidacta y pintaba solo. A los 12 años conocí a un japonés que vendía pinturas y me vendió mis primeros cuadros, por ejemplo, unas copias de Cristo. Comencé a ganarme la vida como copista. Empecé a pintar del natural y en la Herradura pinté "El salto del fraile" y un señor (del cual no recuerdo su nombre) me compró ese cuadro y se hizo mi amigo, preguntándome por qué no iba a la Escuela. Hasta ese momento yo no sabía que existía una Escuela de Bellas Artes y yo ya pasaba de los 20 años.

Cuando Zapata-Orihuela se presentó a la Escuela de Bellas Artes de Lima, todavía era director (por poco tiempo más) el fundador del Indigenismo José Sabogal; y fue Julia Codesido quien le puso los modelos para la prueba de acceso: una planta y un calco o busto para demostrar su capacidad para resolver un retrato. Si tenemos en cuenta que había pasado casi una década dedicado a dibujar y pintar, podemos decir que el maestro ya tenía "la práctica intensiva" necesaria para manejar un oficio de la que hablan los expertos, con la cual "se desarrollan las conexiones cerebrales necesarias para todo aprendizaje"16,17, por lo tanto, lo que le aportaría la Escuela -cuyo ingreso le costó 20 soles de aquellos días- sería el pulir su aprendizaje, las relaciones con otros artistas y ampliar sus horizontes estilísticos. Nos encontramos, entonces, con un ejemplo de lo importante que es que

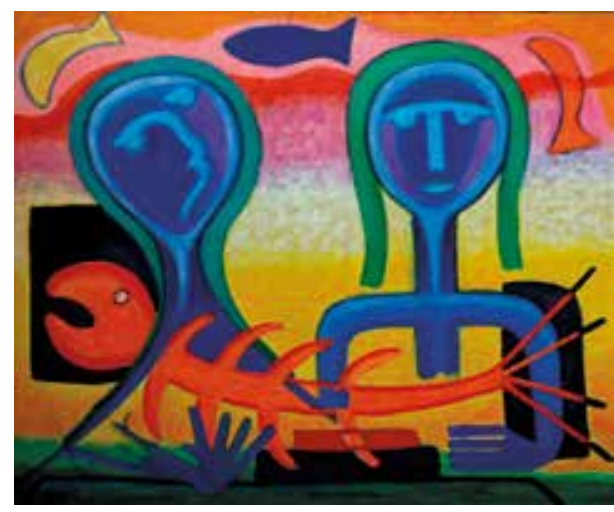

Manuel Zapata Orihuela. La Comida de dos Mujeres, 1986. Óleo / lienzo, 61 x $50 \mathrm{~cm}$. los talentos personales encuentren el medio propicio y los maestros adecuados que incentiven o motiven el máximo desarrollo de una inclinación innata, así como una sociedad receptiva que apoye sus búsquedas (Gardner, ${ }^{18}$ Renzulli ${ }^{19}$ ). Y los maestros que encontró Zapata-Orihuela fueron algunos de los mejores representantes de la plástica nacional en aquella época: Julia Codesido (1883-1979), en sus inicios; José Gutiérrez Infantas (1897-1997), en dibujo; el escultor Ismael Pozo Velit (1905-1959) quien también fue maestro de Héctor Sánchez (19191990), Alberto Guzmán (1927) y Víctor Delfín (1927). Este maestro -autor de La Yunta, una

16 Coyle, 2009: 46-47.

17 Fields, 2010: 768-769.

18 Csikszentmihalyi se preguntó ¿dónde está la creatividad? Y las conexiones necesarias para su desarrollo son descritas en Gardner (1998: 55-57).

19 Renzulli y Smith, 1977: 512-518. 
de las esculturas más emblemáticas del Indigenismo en el Perú- le dejó una honda huella por su humanismo, ternura, capacidad y maestría, además de saber valorar y estimular a los alumnos por su trabajo, como hizo con una mano en perspectiva que él realizó bajo su dirección. Más adelante fue alumno de Quispéz Asín (1900-1983), hermano del poeta César Moro (1903-1956) y del belga Jacques Maes (19051968), aunque de forma extraoficial. Este profesor le dijo: “Ud. no es mi alumno, pero yo quiero ser su profesor porque usted tiene la capacidad de equilibrar un cuadro con cualquier objeto". Lo aceptó con sus alumnos de postgrado de la Escuela y, aunque era un maestro muy sincero y hasta duro, contó con su aprecio permitiendo que hiciese experimentos y ensayos con la espátula. También tuvo la suerte de contar con la aceptación de sus colegas, quizá por su carácter templado y equilibrado, algo que no todos poseían, como Sérvulo Gutiérrez (1914-1961) que muchas veces perdía el control. Sin embargo, el maestro confiesa: "Para yo acalorarme, tiene que pasar mucha agua bajo el puente”. Ese temple, esa capacidad de sus sobrios lóbulos prefrontales ${ }^{20}$ para lidiar con el entorno y con sus propios impulsos, ese saber estar en armonía con los demás, le permitió tener muchos amigos con los que siguió relacionándose, como veremos después. Estudió con Eladio Ruiz (1922-2013), con Pedro Azabache (1918-2012) -quien más adelante sería el fundador de la Escuela de Bellas Artes "Macedonio de la Torre" de Trujillocon Gamaniel Palomino (1921-1991), Julio Camino Sánchez (1914-2007) y Ángel Chávez (1928-1995): todos ellos han dejado su huella en el arte no sólo a nivel nacional sino internacional.

Durante su estancia en la Escuela, Zapata-Orihuela no sólo fue un alumno destacado, muy bien con-

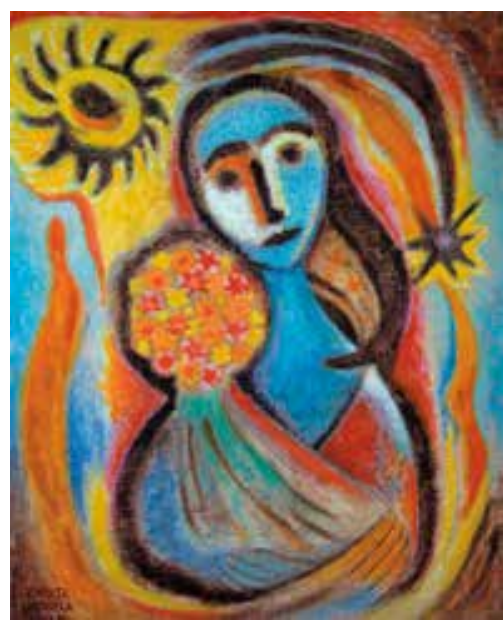

Manuel Zapata Orihuela. Florista con sol, 1990. Oleo / lienzo, 100 × $81 \mathrm{~cm}$.

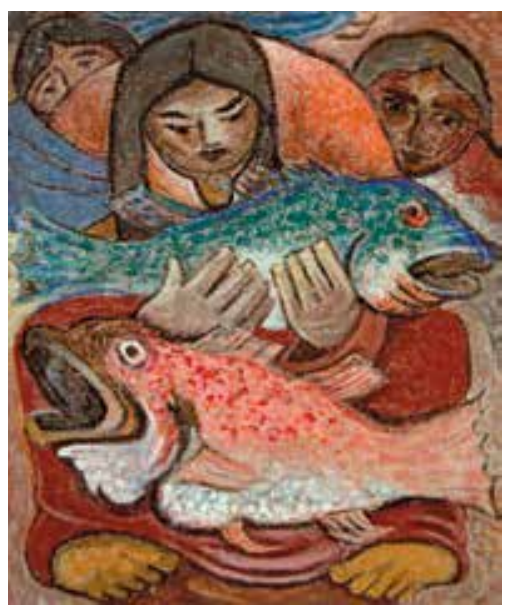

Manuel Zapata Orihuela. Pescadoras en la Playa, 1998. Témpera / yute, $81 \times 65 \mathrm{~cm}$. siderado y relacionado sin dejar de ser independiente y libre pensador; sino que también fue profesor particular de una de las más grandes representantes de la plástica nacional, Tilsa Tsuchiya. Moll dice: "Aparte de sus maestros en la Escuela Nacional de Bellas Artes, Tilsa frecuentó los talleres de Manuel Zapata-Orihuela (1921) y de Eduardo Gutiérrez (1920) ${ }^{21}$ ", algo que corrobora el maestro, ya que él nos relata que ella fue su alumna cuando estaba en la Escuela, estudiando bajo la dirección de Sabino Springett (1913-2006). "El oficio se puede aprender, el arte se puede transmitir...", dice el maestro, convertido en transmisor de memes ${ }^{22}$ y que aún ahora gusta compartir sus experiencias. Lo que aconseja es una práctica constante y consciente para llegar a dominar el lenguaje plástico. La experimentación, la búsqueda del material adecuado para transmitir las vivencias son muy importantes para lograr un lenguaje personal. La reflexión y el

20 Ernst y Fudge, 2009: 367-382.

21 Moll, 1991: 86.

22 Dawkins, 2002: 251. 
autoconocimiento para lograr las más altas cotas creativas pueden ser incentivadas por el medio, pero sin duda cada artista tiene su particular manera de solucionar las cuestiones que se plantea ${ }^{23}$. Y en el caso de su alumna, Tilsa Tsuchiya, pensamos que sin duda fue su gran sensibilidad, la mezcla de culturas y el apoyo que siempre tuvo por parte de su entorno, lo que favoreció la aparición de una artista que impuso su estilo en un momento de apertura hacia nuevas corrientes más acordes con el desarrollo universal del arte, sin que por ello, al igual que Zapata-Orihuela, se olvidara de las fuentes ancestrales de las que había bebido.

Una época convulsa, no sólo en Perú sino en América Latina como describe Mirko Lauer:

Con la aparición del proyecto de desarrollo del Gobierno Militar en 1968 quedaron cortados de raíz, al menos por un tiempo, las bases sociales del movimiento que la crítica llamó ‘la vanguardia’ y una excelente generación de plásticos quedó dividida... ${ }^{24}$

cambió el destino del maestro llevándolo a otro continente, junto con su familia, como escribe Leonardini:

A inicios de la década de 1970 se va a radicar a París. Esto no lo limita para que en julio de 1986, junto con Óscar Allaín, Julio Camino Sánchez, Ángel Chávez y Gamaniel Palomino, integre el grupo "Cinco amigos pintores"; la finalidad de este grupo es rescatar lo peruano a través de un esfuerzo unitario. Dos meses después el grupo se amplía cuando ingresan a él Aquiles Ralli, Enrique Galdós Rivas y el escultor Héctor Sánchez, motivo por el cual se denominan "Ocho amigos del Arte" 25 .

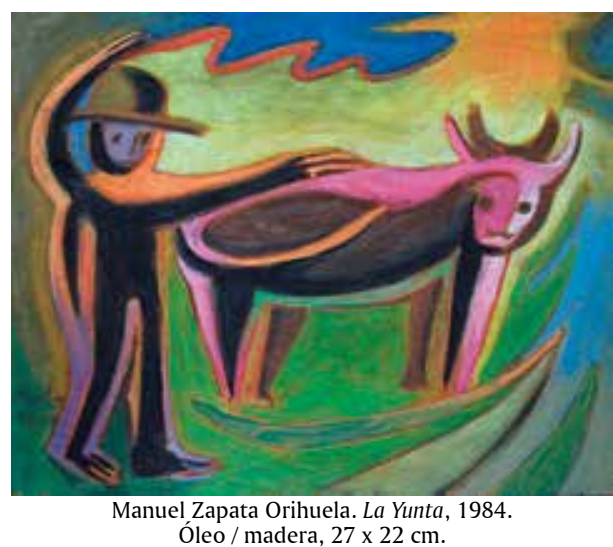

Y son esos amigos los que mantienen a Zapata-Orihuela en contacto con una nueva forma de entender el Indigenismo, muy próxima a las nuevas corrientes artísticas como son el Expresionismo, el Simbolismo o el Neo-realismo, e inclusive un acercamiento hacia la abstracción geométrica con toques andinos. Digamos que en este grupo de amigos el placer estético confluye en un Neo-indigenismo que, gracias a su plasticidad y tolerancia, amplió los horizontes de esa corriente del arte peruano haciéndola más universal y contemporánea. ZapataOrihuela parte del Indigenismo, pero él mismo reconoce "que ha caminado mucho tiempo en solitario", pero que "la soledad no existe cuando el hombre puede pensar y crear. Está muy feliz cuando está solo, aunque es muy sociable también.” Para el maestro: “...la pintura es una búsqueda constante e intensa. Cada obra es una tarea a largo plazo. El color o tono general depende de mi estado de ánimo, de la sensación acerca de lo que quiero comunicar para encontrar la armonía y la belleza.” Y esa lucha por la perfección y el logro del ideal neuroestético es en lo que Zeki coincide con muchos artistas, porque lo que tenemos en nuestro cerebro muchas veces no concuerda con la realidad o con lo que para los demás es lo ideal:

23 Cameron, 2011: 133-147.

24 Lauer, 1976: 166.

25 Leonardini, 2003:194. 
Que la perfección para un individuo no es necesariamente la perfección para otro, es una clara indicación de que no hay un estándar universal de perfección, y por lo tanto que no hay alguna clase de Ideal en el mundo exterior. Si lo hubiese, todos nosotros seguramente tendríamos la misma noción de perfección. Esto es también una guía segura de que la perfección reside en el cerebro en lugar de en el mundo exterior, y se tiene que llegar a ella a través del proceso pensante ${ }^{26}$.

Para el maestro crear y producir van unidos, pero hay que tener mucho cuidado "porque se puede ser muy productivo y poco creativo o a la inversa y eso trae cola, a la larga". Lo importante, dice, es "saber aprovechar las oportunidades como lo hacía Picasso". El maestro nos muestra su taller en el que observamos los distintos materiales que utiliza, como óleos, ceras, tizas, etc., así como objetos y tejidos de su tierra lejana. Nos cuenta que fluye con facilidad cuando trabaja pero demora en hacer su obra porque es muy crítico consigo mismo, nunca está contento con su obra. Siente que nunca se termina una obra. Estas confesiones nos hacen recordar la conexión de los seres humanos en general, y los artistas en particular, con el placer y la persistencia en realizar algo, que muchas veces no es comprendido por los demás, utilizando para ello diversos circuitos cerebrales y sus respectivas neurohormonas:

Querer una cosa y que nos guste esa cosa son dos aspectos distintos del placer, en donde entran en juego sistemas de neurotransmisores distintos. Son los opioides los que proporcionan el barniz del placer a nuestras experiencias, mientras que la dopamina hace que volvamos a buscar más ${ }^{27}$.

Aunque su obra es un reflejo de la realidad, es muy intuitivo y podría calificársele como un neo-indigenista simbólico y expresionista. A sus años, mantiene su templanza y su sentido de humor, diciendo que le gusta que admiren su obra, pero más le gustaría que se la compren. Es un conocedor del sistema y del mercado del arte muy consciente de la dificultad de ser original, porque muchas veces al ser muy innovador no eres valorado por el gusto imperante. Siempre le han atraído las técnicas antiguas, pero aportando algo de uno mismo: la creatividad es saber reinventarse y fluir produciendo. A nuestro artista le preocupa la contamina-

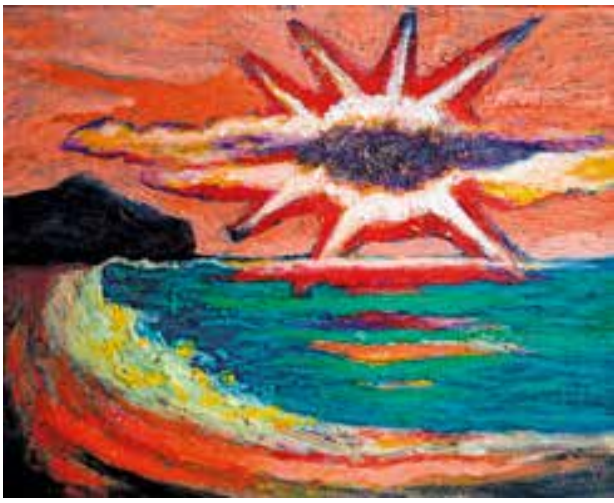

Manuel Zapata Orihuela. Playa de la Chira, 2015. Encáustica / lienzo, $41 \times 33 \mathrm{~cm}$. ción, la polución, la deshumanización, coincidiendo con el perfil de creativo que dibuja Cloninger ${ }^{28}$. Sin embargo, no se hunde en la melancolía y tiene una mentalidad positiva, como nos lo expresó con mucho entusiasmo y energía:

Es preciso criticar y denunciar a la sociedad: no se debe callar. Todo este caos es un indicador de la decadencia que estamos pasando, sin embargo soy optimista: de esto puede salir algo. Soy optimista, creo que habrá cambios. Y aunque los valores humanos se están perdiendo, el ser humano tiene aún mucho que

26 Zeki, 2009: 50-51.

27 Fox, 2012: 78.

28 Cloninger, 2013: 16-24. Para Cloninger el verdadero creativo no sólo es un ser organizado y capaz de resolver sus propios problemas, sino que además tiene un alto grado de consciencia social y espiritualidad. 
recorrer. Y así como el hierro necesita los golpes para ser forjado, el ser humano necesita las dificultades. Del desorden tendrá que salir algo nuevo. De lo malo se aprende, para no volver a hacerlo.

Para terminar la entrevista, le preguntamos qué pensaba sobre la muerte y nos contestó que no cree que aquí sea el fin. Cree en los mundos paralelos, no en una continuación, sino un mundo invisible en el cual pueda seguir pintando, en otra realidad. Zapata-Orihuela nos dice que él va a seguir pintando sus recuerdos del Perú, en ésta o en otras realidades. La obra de nuestro artista es un ejercicio de memoria no sólo personal sino colectiva. Nos transporta con sus colores, formas, texturas y composición hasta los paisajes olvidados del Perú profundo, no hacia aquella patria ancestral plena de reminiscencias arqueológicas, sino a la que aún se puede encontrar en los pequeños y lejanos pueblos que conservan esa sabiduría existencial que las sociedades contemporáneas adelantadas deberían observar. 72 años después de que el maestro Zapata-Orihuela se acercara a beber de las fuentes de la Escuela Nacional Superior Autónoma de Bellas Artes del Perú, todavía podemos encontrar neo-indigenistas reinventados en las distintas corrientes del arte del siglo XX. Postcubistas, geométricos, neo-figurativos, simbolistas o neo-expresionistas, han seguido el hilo conductor del Indigenismo ya sea como denuncia, contemplación, costumbrismo o fusión con las más diversas expresiones neuroestéticas ${ }^{29}$. Gracias a los nuevos medios y a la tecnología descubrimos que no es necesario hacer parcelas, sino que se tiende a la integración. Por ejemplo, contemplar una tumba pre-hispánica o las líneas de Nazca puede ser motivo de inspiración para que los nuevos artistas realicen una instalación apoyados en el arte popular o se atrevan con el Land Art. El pensamiento de nuestro artista, con respecto a las nuevas tendencias, es tan plástico como su obra, por eso opina que en el arte "lo más importante es la libertad y la honestidad.” Sus obras hablan por sí mismas, apoderándose de un espacio en nuestra memoria visual y emocional. Sin duda alguna, Zapata-Orihuela es uno de los más importantes y significativos representantes de la plástica nacional.

29 En la Feria Estampa (Madrid, 2015) en la cual Perú ha sido país invitado, hemos observado a Durand, Hirose, Revilla, Patrucco, Acha-Kutscher, Estrems, Isasi, Alayza, Barbosa y Bryce, haciendo gala de fusión tecnológica y consciencia ecológica-social. 


\section{Referencias bibliográficas}

Buntix, Gustavo y Luis Eduardo Wuffarden

2003 Mario Urteaga. Nuevas miradas. Lima: Museo de Arte de Lima \& Fundación Telefónica.

Cameron, Julia

2011 El Camino del Artista: Un Curso de Descubrimiento y Rescate de tu Propia Creatividad. Madrid: Santillana.

\section{Casafont, Rosa}

2012 Viaje a tu Cerebro. El Arte de Transformar tu Mente. Barcelona: Ediciones.

\section{Cloninger, Robert}

2013 "What Makes People Healthy, Happy, and Fulfilled In The Face Of Current World Challenges?" Mens Sana Monograph, 1(11), 16-24. http://www.ncbi.nlm.nih. gov/pmc/articles/PMC3653221/ [Consulta: 21 de enero, 2014].

Coyle, Dan

2009 Las Claves del Talento. ¿Quién dijo que el talento es innato? Aprende a Desarrollarlo. Barcelona: Planeta.

Csikszentmihalyi, Mihaly

2007 Aprender a Fluir (5 ${ }^{\mathrm{a}}$ ed.). Barcelona: Kairós.

Dawkins, Richard

2002 El gen egoísta. Las bases biológicas de nuestra conducta. Barcelona: Salvat Editores.

Ernst, Monique \& Fudge, Julie

2009 A developmental neurobiological model of motivated behavior: anatomy, connectivity and ontogeny of the triadic nodes. Neuroscience and Biobehavioral Reviews, 3(33), 367-382. http://www.ncbi.nlm.nih. gov/pmc/articles/PMC2696617/ [Consulta: 4 de junio, 2010].

Fields, Douglas

2010 "Change in the brain's white matter. The role of the brain's white matter in active learning and memory may be underestimated". Science, 6005(330), 768-769. http://www.ncbi.nlm.nih.gov/pmc/articles/PMC3201847/ [Consulta: 2 de noviembre, 2014].

Fox, Elaine

2012 Una Mente Feliz. Descubre cómo funciona el Optimismo y cambia tu forma de ver la Vida. Madrid: Ediciones Planeta.

Gardner, Howard

1998 Mentes creativas. Una anatomía de la creatividad. Barcelona: Paidós Ibérica.

\section{Lauer, Mirko}

1976 Introducción a la pintura peruana del S. XX. Lima: Mosca Azul.

1992 "La pintura indigenista peruana: una visión de los años noventa”. En: Voces de Ultramar. Arte de América Latina: 19101960. Waugh, Carmen (Comisaria): 73-79. Catálogo de exposición. Centro Atlántico de Arte Moderno. 7 de septiembre-8 de Noviembre de 1992. Las Palmas de Gran Canaria. Casa de América de Madrid. 10 de diciembre de 1992- 31 de enero de 1993. Madrid: Turner Libros.

\section{Leonardini, Nanda}

2003 El grabado en el Perú republicano. Diccionario histórico. Lima: Fondo Editorial Universidad Nacional Mayor de San Marcos.

Lucie-Smith, Edward

1994 Arte Latinoamericano del siglo XX. Barcelona: Destino.

Moll, Eduardo

1991 Tilsa Tsuchiya. Lima: Editorial Navarrete.

Mora Costilla, $\mathbf{M}^{\mathrm{a}}$ del Socorro

2015 Creatividad \& Melancolía. Un estudio psicobiológico de las dimensiones de la personalidad en el artista plástico contemporáneo. Tesis doctoral para optar el grado de Doctora en Bellas Artes, Departamento de Dibujo I, Facultad de Bellas Artes, UCM. Madrid: Asmat \& MoraC Editores.

Mujica, Marisa

2006 Perú. 10.000 años de pintura. Lima: Muxica Editores.

Moya-Albiol, Luis; Herrero, Neus y Consuelo Bernal

2010 "Bases neuronales de la empatía". Revista de Neurología, 50: 89-100.

Punset, Eduardo

2011 El alma está en la red del cerebro. Entrevista a Joaquín Fuster (2011). http://www. redesparalaciencia.com/6374/redes/redes-110-el-alma-esta-en-la-red-del-cerebro [Consulta: 24 de noviembre, 2014].

Renzulli, Joseph \& Linda Smith

1977 "Two approaches to identification of gifted Students". Exceptional Children, 8(43), 512-518.

Rich, Adrienne

2005 Artes de lo posible. Ensayos y conversaciones. Madrid: horas y HORAS, la editorial.

\section{Román, Élida}

2004 "Breve mirada a la pintura peruana del siglo XX”. En: Pintura Peruana Contemporánea. Huertas Muñoz, José Eduardo (comisario): 13-33. Catálogo de exposición realizada en Córdoba en la Sala de Exposiciones Museísticas Caja Sur del 11 de mayo al 5 de junio. Córdoba: Cajasur.

Ugarte Eléspuru, Juan Manuel

1970 Pintura y Escultura en el Perú Contemporáneo. Lima: Editorial Universitaria.

Zeki, Semir

2009 Splendors and Miseries of the Brain. Love, Creativity, and the Quest for Human Happiness. Oxford: Wiley-Blackwe. 